\title{
Implementasi dan Pelatihan Aplikasi Kasir Online Berbasis Android Pada UMKM Marikh Salatiga
}

\author{
Nina Setiyawati ${ }^{1}$, Dwi Hosanna Bangkalang ${ }^{2}$ \\ Fakultas Teknologi Informasi, Universitas Kristen Satya Wacana ${ }^{1,2}$ \\ e-mail: nina.setiyawati@uksw.edu, dwihosanna.bangkalang@uksw.edu²
}

\begin{abstract}
Abstrak
Marikh Salatiga adalah salah satu usaha mikro, kecil, dan menengah (UMKM) di Salatiga yang bergerak di bidang kuliner di mana pencatatan transaksinya masih dilakukan secara manual. Hal ini mengakibatkan beberapa permasalahan seperti data transaksi tidak terkelola dan tidak tersimpan dengan baik. Melihat permasalahan tersebut maka Marikh Salatiga membutuhkan sebuah sistem informasi khususnya transaction processing system di mana salah satu contohnya adalah aplikasi kasir untuk mengakomodasi proses pencatatan transaksi rutin harian yang diperlukan guna menjalankan bisnis. Pada kegiatan pengabdian masyarakat ini dilakukan pembangunan dan implementasi aplikasi kasir online berbasis Android yang diharapkan dapat mengakomodasi pencatatan transaksi di Marikh Salatiga. Adapun aplikasi yang dibangun memberikan dampak positif bagi Marikh Salatiga yaitu membantu efisiensi operasional serta mendukung pengambilan keputusan strategi yang berbasis data.
\end{abstract}

Kata kunci: Aplikasi kasir, transaction processing system, Android, UMKM

\section{Abstract}

Marikh Salatiga is one of the micro small and medium enterprises (MSMEs) in Salatiga which is engaged in the culinary field where the recording of transactions is still done manually. This has resulted in several problems such as poorly manage and stored of the transaction data. Seeing these problems, Marikh Salatiga needs an information system, especially a transaction processing system (Point of Sales Application) to accommodate the process of recording the daily routine transactions needed to run the business. In this community service activity, an Androidbased online Point of Sales application was developed and implemented which is expected to accommodate the recording of transactions at Marikh Salatiga. The development of this application has a positive impact on Marikh Salatiga, such as helping operational efficiency and supporting data-based strategic decision making.

Keywords: Point of sales application, transaction processing system, Android, MSMEs

\section{PENDAHULUAN}

Marikh Salatiga merupakan salah satu Usaha Mikro Kecil dan Menengah (UMKM) di Salatiga yang bergerak di bidang kuliner di mana pencatatan transaksinya masih dilakukan secara manual. Hal tersebut memunculkan beberapa permasalahan seperti: 1) data transaksi tidak terkelola dengan baik sehingga informasi terkait jumlah penjualan produk, pelanggan, waktu ramai, dan data-data lainnya yang merupakan dasar pengambilan keputusan strategi manajemen tidak terekam; 2) data arus pendapatan dan pengeluaran tidak tercatat dengan lengkap 3) risiko kecurangan dan kesalahan yang dilakukan oleh manusia. Pencatatan yang dilakukan secara manual juga mengakibatkan keutuhan dan keabsahan data tidak terjamin.

Melihat permasalahan-permasalahan tersebut maka Marikh Salatiga membutuhkan sebuah sistem informasi yang merupakan sekumpulan komponen yang terintegrasi untuk mengumpulkan, menyimpan, dan memproses data dan untuk mendistribusikan informasi (Falih, 2018; Satoto dkk., 2016) dan pengetahuan. Sistem informasi terbukti telah menjadi salah satu komponen paling relevan dari lingkungan bisnis (Abrego Almazán dkk., 2017) serta bagian penting dalam suatu perusahaan atau organisasi untuk menjalankan dan mengelola operasional, berinteraksi dengan pelanggan dan pemasok, bersaing di pasar, dan mendukung pengambilan keputusan (Pramitha, 2017; Zwass, 2020). Oleh karena itu, tidak mengherankan jika dikatakan bahwa setiap organisasi bisnis di era ini membutuhkan sistem informasi untuk melacak semua aktivitas bisnis, mulai dari perencanaan bisnis, hingga pengiriman 
produk (Palmius, 2010) melalui manufaktur dan siklus kualitas (Nowduri \& DBA, 2012), di mana hal ini akan memberikan dampak positif pada produktivitas dan daya saing perusahaan.

Sistem informasi mengakomodasi aspek-aspek penting dalam perusahaan berdasarkan level manajemen atau biasa disebut dengan piramida sistem informasi seperti yang terlihat pada Gambar 1 (O'Brien \& Marakas, 2011). Pada level piramida paling bawah terdapat Transaction Processing System (TPS) yang membantu pengendalian dan pelacakan aktivitas transaksi dasar perusahaan dengan memberikan informasi kepada perusahaan (Laudon \& Laudon, 2012) seperti: 1) informasi tentang pesanan penjualan yang dibuat dengan pelanggan; 2 ) pelacakan inventaris; 3 ) penerimaan produk yang dibeli dari pemasok eksternal. Oleh karena itu TPS merupakan alat pendukung aktivitas bisnis sehari-hari serta alat pemantauan yang penting (Zago \& Mesquita, 2015). Salah satu contoh TPS adalah aplikasi kasir yang mengakomodasi proses pencatatan transaksi rutin harian yang diperlukan untuk menjalankan bisnis (Laudon \& Laudon, 2012).

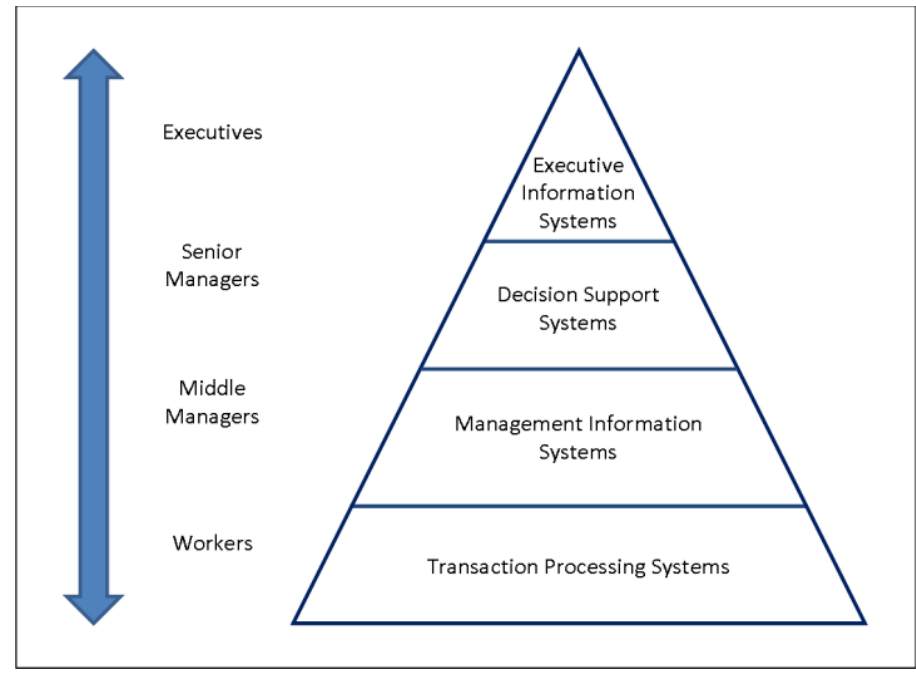

Gambar 1. Piramida Sistem Informasi

Pada kegiatan pengabdian kepada masyarakat (PKM) ini dilakukan pembangunan dan implementasi aplikasi kasir online berbasis Android pada UMKM Marikh Salatiga yang diharapkan dapat membantu untuk mengatasi permasalahan-permasalahan yang dialami.

\section{METODE}

Metode pelaksanaan pengabdian kepada masyarakat ini terlihat pada Gambar 2.

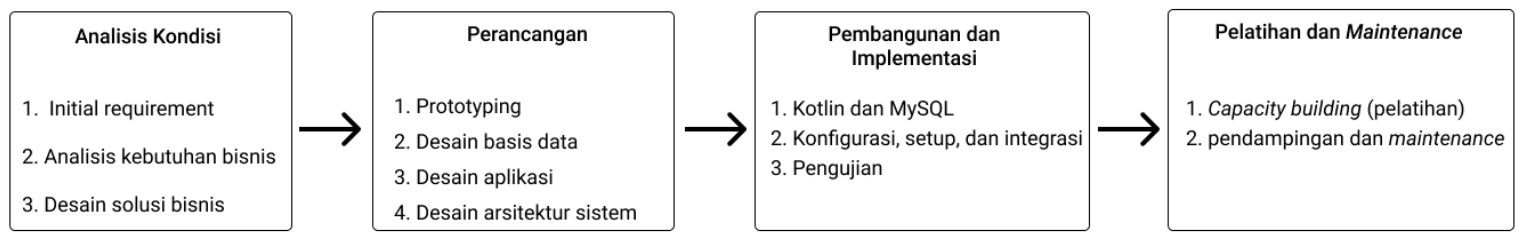

Gambar 2. Metode Pelaksanaan PKM

Pada tahap pertama yaitu analisis kondisi, dilakukan wawancara dan focus group discussion (FGD) dengan mitra yang dalam kegiatan PKM ini adalah Marikh Salatiga. Dari FGD dan wawancara didapatkan beberapa permasalahan yang muncul dalam proses transaksi Marikh Salatiga. Berdasarkan 
permasalahan-permasalahan tersebut, maka sebagai upaya untuk menanganinya, dilakukanlah pembangunan aplikasi kasir online berbasis Android. Mengacu pada salah satu fungsi sistem informasi yaitu meningkatkan efisiensi (Abrego Almazán dkk., 2017; Bani-Hani dkk., 2009; Boell \& CecezKecmanovic, 2015) dan keberhasilan operasional (Haag \& Cummings, 2009), maka diharapkan dengan aplikasi kasir online akan membantu mitra untuk mengakomodasi proses transaksi yang selama ini manual serta penyimpanan daftar histori transaksi yang pada awalnya tidak tersimpan dengan baik. Pada tahap ini, kebutuhan aplikasi juga digali sebagai dasar perancangan aplikasi.

Pada tahap kedua yaitu perancangan, dilakukan perancangan sistem berdasarkan kebutuhan yang telah didapatkan pada tahap sebelumnya. Adapun desain yang dilakukan mulai dari desain basis data, desain antar muka pengguna, desain sistem, dan arsitektur aplikasi.

Tahap ketiga adalah pembangunan aplikasi yang dilakukan menggunakan bahasa pemrograman Kotlin yang mudah digunakan (Lotze, 2018), menawarkan pemrograman fungsional dengan pemrograman berorientasi objek (Narang \& Tuli, 2017), dan memiliki sifat interoperabilitas (JetBrains, 2020). Adapun basis data yang digunakan adalah MySQL. Tahap selanjutnya adalah pelatihan dan pendampingan penggunaan aplikasi kepada pemilik dan pegawai Marikh Salatiga serta maintenance aplikasi.

\section{HASIL DAN PEMBAHASAN}

Aplikasi kasir online berbasis Android yang telah dibangun dan diujicoba, diterapkan di Marikh Salatiga yang kemudian dilanjutkan dengan pelatihan penggunaan aplikasi tersebut. Pelatihan diikuti oleh 1 pemilik dan 4 pegawai Marikh Salatiga. Pelatihan diawali dengan menjelaskan cara login di aplikasi untuk dapat masuk pada halaman utama seperti yang terlihat pada Gambar 3.

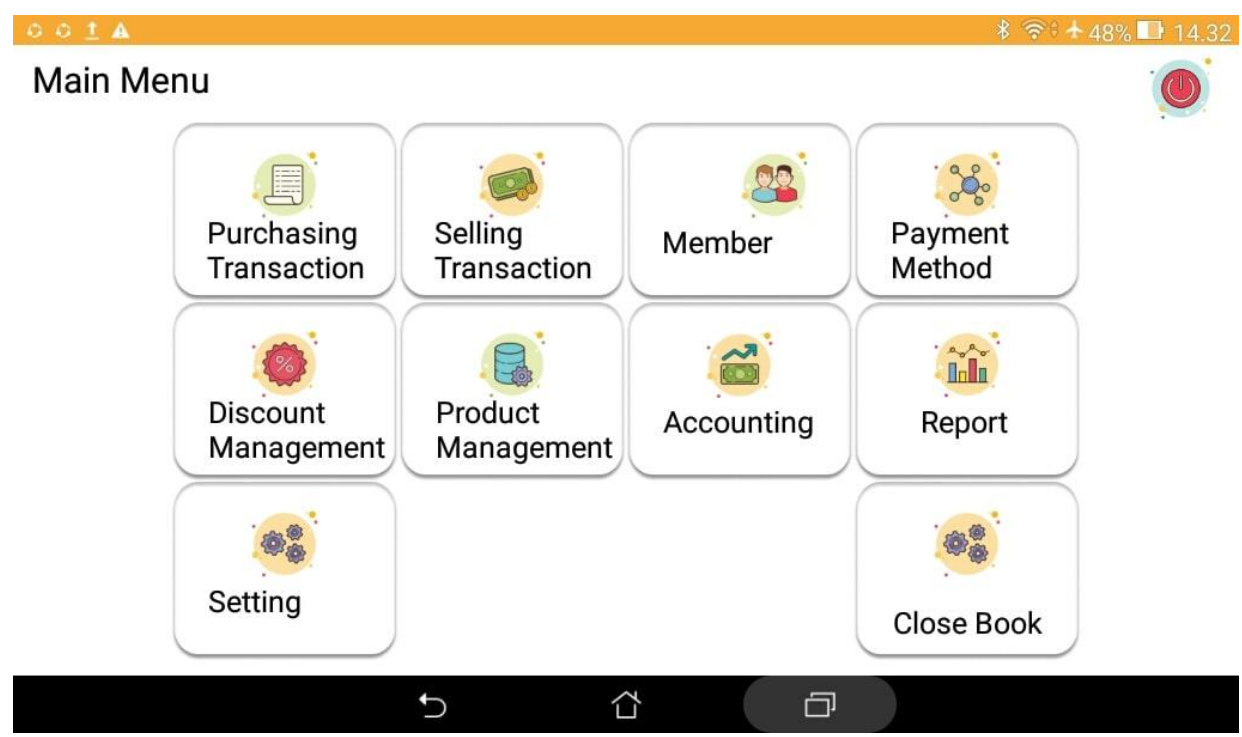

Gambar 3. Tampilan Halaman Utama Aplikasi

Pada Gambar 3 terlihat beberapa menu pada aplikasi kasir yan diterapkan pada mitra Marikh Salatiga yaitu: 1) Purchasing Transaction, adalah menu untuk mengelola pembelian bahan baku untuk produksi makanan dan minuman serta pengeluaran keuangan lainnya seperti listrik, air, internet, dll.; 2) Selling Transaction, adalah menu untuk mengelola transaksi penjualan; 3) Payment Method, adalah menu untuk mengelola jenis-jenis pembayaran yang bisa dilakukan di Marikh Salatiga seperti cash, Gopay, OVO, dll; 4) Discount Management, adalah menu untuk mengelola diskon untuk transaksi penjualan; 5) Product Management, adalah menu untuk mengelola produk, harga, stok, kategori produk 
serta data catatan yang digunakan untuk memberi tambahan informasi pada makanan dan minuman yang dijual; 6) Close Book, adalah menu yang digunakan untuk melakukan tutup buku setelah jam operasional Marikh selesai. Pada kegiatan PKM ini belum dilakukan proses pembangunan menu Accounting dan Report.

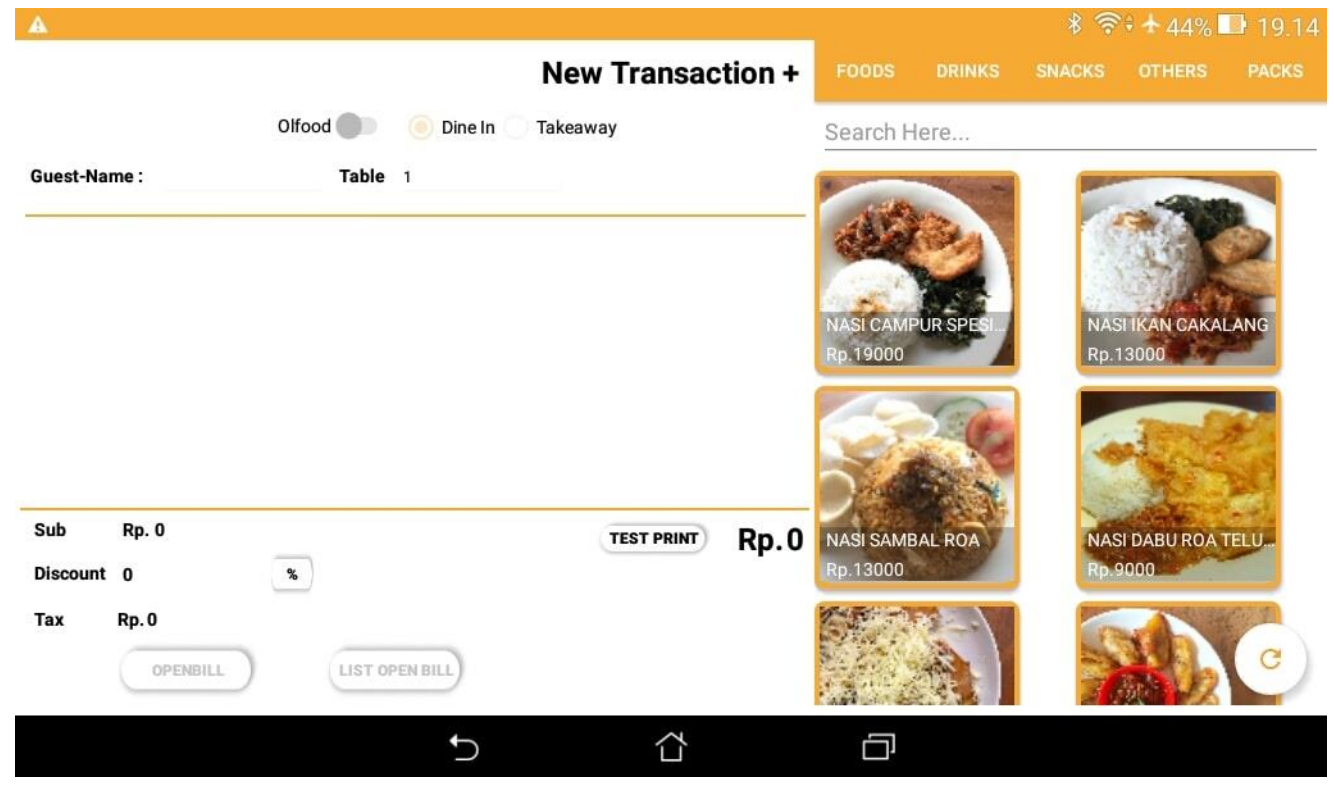

Gambar 4. Tampilan Halaman Transaksi

Gambar 4 adalah tampilan halaman transaksi di mana kasir dapat memasukkan penjualan makanan dan/atau minuman. Pada halaman ini, beberapa aktivitas pendukung transaksi dapat dilakukan, seperti: 1) Memasukkan nama pelanggan; 2) Memasukkan makanan dan/atau minuman yang dibeli pelanggan; 3) Memberikan catatan pada makanan dan/atau minuman yang dibeli pelanggan; 4) Memasukkan pilihan transaksi yang dilakukan apakah merupakan online food atau reguler; 5) Memasukkan pilihan jenis transaksi reguler; 6) Memasukkan transaksi pada list open bill; 7) Melakukan pembayaran dan pilihan metode bayar.

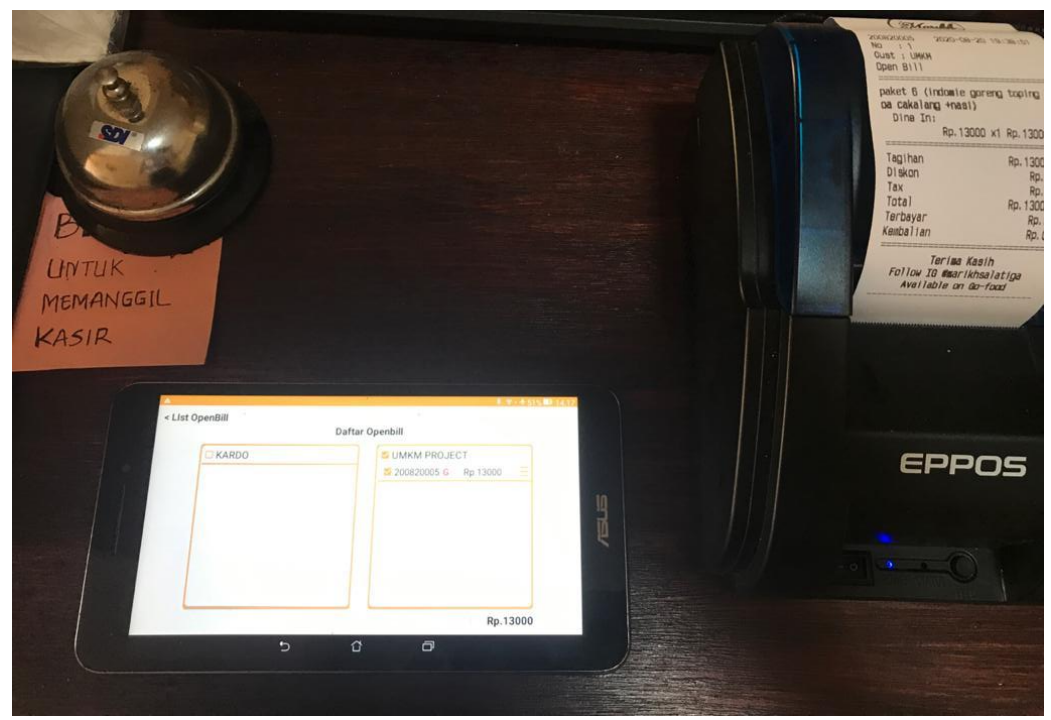

Gambar 5. Nota Hasil Aplikasi 
Gambar 5 menunjukkan proses cetak nota dari transaksi yang dilakukan oleh pelanggan. Adapun printer yang digunakan harus memiliki teknologi bluetooth untuk koneksi dengan piranti smartphone atau tablet Android yang digunakan. Gambar 6 memperlihatkan halaman histori transaksi yang menyimpan transaksi-transaksi yang dilakukan. Pada halaman ini terdapat fungsi filter tanggal untuk melihat transaksi pada jangkauan tanggal yang dipilih. Adapun informasi lain yang ditampilkan pada halaman transaksi adalah nominal transaksi, metode bayar yang digunakan, komisi yang dipotong dari nominal transaksi jika jenis transaksinya online food, serta total komisi dan total nominal dari transaksitransaksi tersebut.

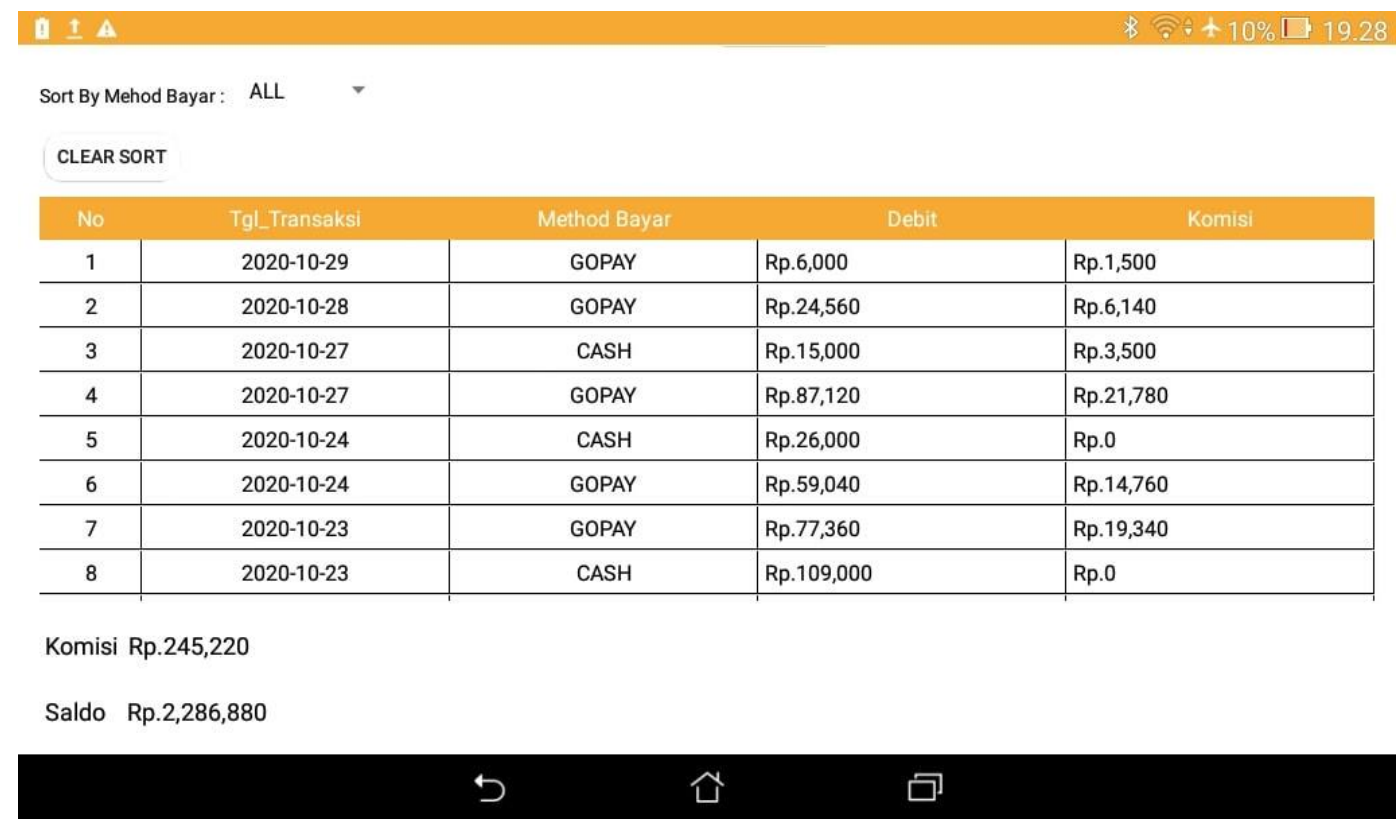

Gambar 6. Tampilan Histori Transaksi

Dari kegiatan PKM yang telah dilakukan, mitra dapat merasakan beberapa dampak positif seperti: 1) Proses transaksi yang lebih efisien; 2) Mitra memiliki data pembeli, produk dan stok yang dapat dilihat secara waktu nyata; 3 ) Histori transaksi tersimpan dengan baik, sehingga dapat dengan mudah dilihat kembali. Dari data transaksi juga bisa dilihat data lain seperti jam ramai pengunjung, produk yang sering dibeli, pembeli yang sering datang. Hal ini dapat membantu mitra dalam menentukan strategi ke depannya.

\section{SIMPULAN}

Kegiatan PKM yang dilakukan di mitra Marikh Salatiga yang merupakan UMKM yang bergerak di bidaang kuliner telah memberikan dampak positif bagi mitra di mana mitra dapat melakukan digitalisasi pencatatan transaksi dan pengelolaan histori transaksi yang terjadi. Selain membantu efisiensi operasional mitra, juga mendukung pengambilan keputusan strategi yang berbasis data.

\section{DAFTAR REFERENSI}

Abrego Almazán, D., Sánchez Tovar, Y., \& Medina Quintero, J. M. (2017). Influence of information systems on organizational results. Contaduria y Administracion, 62(2), 321-338. https://doi.org/10.1016/j.cya.2017.03.001

Bani-Hani, J. S., Al-Ahmad, N. M. M., \& Alnajjar, F. J. (2009). the Impact of Management Information 
Systems on Organizations Performance: Field Study At Jordanian Universities. Review of Business Research, 9(17), 127-137. http://ezproxy.library.uvic.ca/login?url=http://search.ebscohost.com/login.aspx?direct=true\&db=b th\&AN=45462891\&site=ehost-live \&scope=site

Boell, S. K., \& Cecez-Kecmanovic, D. (2015). What is an information system? Proceedings of the Annual Hawaii International Conference on System Sciences, 2015-March(January), 4959-4968. https://doi.org/10.1109/HICSS.2015.587

Falih, F. (2018). A Review Study of Information Systems. International Journal of Computer Applications, 179(18), 15-19. https://doi.org/10.5120/ijca2018916307

Haag, S. H., \& Cummings, M. (2009). Management Information Systems for the Information Age. McGraw-Hill, Inc.

JetBrains. (2020). Kotlin Language Documentation.

Laudon, K. C., \& Laudon, J. P. (2012). Management information systems: managing the digital firm. Prentice Hall. https://doi.org/10.1590/s1415-65552003000100014

Lotze, B. K. (2018). GETTING STARTED WITH KOTLIN : A RESOURCE GUIDE.

Narang, J., \& Tuli, E. S. (2017). Review Study on New Era of Android Kotlin. International Journal of Technology and Computing, 3(8), 271-273.

Nowduri, S., \& DBA, S. A.-D. (2012). Management Information Systems and Its Support to Sustainable Small and Medium Enterprises. International Journal of Business and Management, 7(19), 125131. https://doi.org/10.5539/ijbm.v7n19p125

O’Brien, J. A., \& Marakas, G. M. (2011). Management Information Systems. McGraw-Hill.

Palmius, J. (2010). Organization-Level Information Systems Tools for Supporting the Development Process. In Physics.

Pramitha, D. (2017). Pergeseran Paradigma Sistem Informasi Manajemen. J-MPI (Jurnal Manajemen Pendidikan Islam), 2(1). https://doi.org/10.18860/jmpi.v2i1.4356

Satoto, K. I., Martono, K. T., Isnanto, R. R., \& Kridalukmana, R. (2016). Design of management information systems research, publications and community service. ICITACEE 2015 - 2nd International Conference on Information Technology, Computer, and Electrical Engineering: Green Technology Strengthening in Information Technology, Electrical and Computer Engineering Implementation, Proceedings, 117-122. https://doi.org/10.1109/ICITACEE.2015.7437782

Zago, C. F., \& Mesquita, M. A. de. (2015). Advanced Planning Systems (Aps) for Supply Chain Planning: a Case Study in Dairy Industry. Brazilian Journal of Operations \& Production Management, 12(2), 280. https://doi.org/10.14488/bjopm.2015.v12.n2.a8
Zwass, $\quad V$
V. (2020).
Information
system.
Encyclopædia
Britannica.

https://www.britannica.com/topic/information-system 